\title{
The Best Chance For All: A Policy Roadmap for Post-Pandemic Panic
}

\author{
Sally Kift \\ James Cook University, Australia \\ Nadine Zacharias \\ Swinburne University of Technology, Australia \\ Matt Brett \\ Deakin University, Australia
}

\begin{abstract}
The Best Chance for All was developed in 2018 as a long-term policy vision for student equity in Australian tertiary education. We argue in this article that COVID-19 has exacerbated the issues that the policy vision sought to address and has increased demands on and of post-secondary education. Specifically, we argue that the magnitude of the social and economic challenges presented by COVID-19 warrants holistic policy responses that enable the transition to a connected tertiary education system; one designed to deliver choice and flexibility for lifelong learners. A roadmap for this transition exists in the form of The Best Chance For All. The vision can be actuated through demand driven funding arrangements across tertiary education that are coherently aligned to optimise the performance of both the higher and vocational education sectors and are underpinned by sustained investment in equity outreach and support.
\end{abstract}

Keywords: Student equity; policy; lifelong learning; tertiary education; educational ecosystem.

\section{Introduction}

In the wake of the global Coronavirus disease (COVID-19) pandemic, the economic and social settings of the Australian higher education (HE) sector have changed fundamentally since the beginning of 2020. Limitations of Australian HE business and operating models have been exposed. The closure of international and state borders has prevented international students from (re-)entering the country, and impeded the mobility of domestic students and staff. For those universities whose delivery models were predominantly built around face-to-face teaching and support, the enforcement of lockdowns and physical distancing brought campus life to an abrupt halt.

Compounding the financial shock and delivery disruption, the Federal Government enacted its Job-Ready Graduates Package of HE reforms in October 2020 (the Higher Education Support Amendment (Job-Ready Graduates and Supporting Regional and Remote Students) Act 2020 [JRGP]). The JRGP promises more domestic student places by reducing average government funding per student place. The decrease in average government funding masks significant changes (both increases and decreases) to both student contributions and university revenue by discipline. The net effect of the JRGP to base funding on the long-term patterns of participation is unclear but the short-term university response is increasingly evident. The combined effects of a collapse in international revenue, the economics of transitioning from on-campus to digital delivery, and changes

Except where otherwise noted, content in this journal is licensed under a Creative Commons Attribution 4.0 International Licence. As an open access journal, articles are free to use with proper attribution. ISSN: 2205-0795 
to base funding are leading to substantial cuts to staffing levels (Tija et al., 2020) and courses (Marshman \& Larkins, 2020), especially for those universities that had to pivot sharply in their funding and/or delivery models.

Taken together, these developments introduce risk and uncertainty for advancing HE student equity. This article explores the consequences of the pandemic for the possibilities and limits of the Australian post-secondary education system and, specifically, its potential to successfully engage students from equity cohorts. The conceptual framework for this exploration is The Best Chance for All, a long-term policy vision for student equity in Australian tertiary education developed as a sectorwide collaboration during 2018 (Zacharias \& Brett, 2019), hereafter referred to as 'the equity roadmap'. This framing of equity is consistent with international work, notably the UNESCO Institute for Lifelong Learning (UIL) (2020), which also calls for lifelong learning to move up the policy agenda and for it to be recognised as both a common good and a human right in the post-COVID world.

\section{Emerging Literature on the Impact of COVID-19 on the Australian Education System}

The disruptive nature of COVID-19 has catalysed publication of countless accounts of its immediate impacts on education, and prognostication of its long-term influence. The literature includes reference to structural and systemic inequities across our siloed education sectors having been exacerbated by COVID-19. For example, the Grattan Institute (Sonnemann \& Goss, 2020) found that the achievement gap in schooling between disadvantaged students and their peers grew at three times the usual rate during the period of remote learning in 2020, affecting the pipeline of equity group students accessing and successfully participating in HE. Vocational education and training (VET), with its reliance on practical and work-based learning, has struggled to adapt as workplaces shut down (Schleicher, 2020). And, despite our best pedagogical efforts in HE to support students with complex needs, the impact of the rapid shift to off-campus learning, teaching and support has not fallen evenly for learners (Harvey, 2020). Digital poverty has been an overarching concern (Stone \& David, 2020; Thomas et al., 2020). Many students have experienced educational disadvantage for the first time, while others already in its thrall have had their marginalisation exacerbated (United Nations, 2020).

We are still early in the recovery phase, but it is clear that COVID-19 and its associated lockdowns have substantially increased workforce precarity for all. The options for young people seeking employment or alternative experiences (for example, a gap year to work or travel overseas) have been particularly limited. It is therefore likely that demand for HE will increase substantially into 2021 and beyond (Plibersek, 2020). The political arithmetic of HE's role in the economy's rebuilding, and normalised expectations that places will be available for young people from high- and mid-socioeconomic status (SES) backgrounds, make future growth in places inevitable. This suggests that the recent policy changes wrought by the JRGP may have a short half-life. In the interim however, competition for places will be fierce amongst a growing number of school leavers and mature age students looking to up- and/or re-skill.

Crises can present opportunities for transformative change. The COVID-19 inflection point offers a unique opportunity for reform of Australian HE equity policy and practice, which has, like all policy, been prone to hyper-incrementalism (Jones \& Baumgartner, 2005). If we are to use the current crisis to advance a more equitable, integrated and effective tertiary education system, now is the time for educators, leaders and policy makers to think critically about the policy ideas "lying around" (Friedman, 1982, p. 6) that can be mobilised for a more cohesive, just and equal society. In this article, we utilise the equity roadmap as the conceptual framing to understand how the nation's post-COVID-19 future might lead to a more inclusive, fair and productive Australia.

\section{Method and Conceptual Framing}

The genesis of this article was an abstract submitted by these authors to a conference to explore vulnerabilities of Australian $\mathrm{HE}$ arising from climate change, globalisation, demographic shifts, the need to improve educational outcomes for Australia's First Peoples, the transition to Industry 4.0 and the pandemic. Despite the subsequent cancellation of the conference due to the pandemic, the authors were keen to make sense of the history unfolding around us as proponents of student equity and key participants in the process that led to the publication of the equity roadmap. We chose to re-convene as trusted collaborators, with the intent of exploring the policy implications of the pandemic in the context of the Student Success Special Issue. 
Each of the authors has an extensive background in HE leadership and management and an established track record of research and scholarship in equity policy and practice. Two are Equity Research Fellows with the Australian National Centre for Student Equity in HE (NCSEHE) and the third is a Visiting Professorial Fellow with the NCSEHE, who previously served as a Deputy Vice-Chancellor (Academic). Throughout 2020 we met on a regular basis, employing the 'three Rs' of an action research methodology (Robertson, 2000). We shared our experiences with frank and generous 'reciprocity'; 'reflected' on the reality of those experiences building upon our knowledge base and informing action in our respective professional domains; and, within our respective leadership roles, were critically aware of the need to adapt and adjust our approach, to be 'reflexive' to the dynamic context. Throughout these conversations, the equity roadmap emerged as a robust framework to make sense of the challenges facing our sector, and as one which could inform policy responses to support a sustainable path to post-pandemic recovery.

Public policy can be a messy business, albeit with carefully designed and staged elements that align with the idealised policy cycle (Bridgman \& Davis, 2005). The equity roadmap was the product of a deliberately structured agenda-setting process (see Zacharias \& Brett, 2019 for full details on the methodology). Throughout 2018, the NCSEHE convened legacy and capacity building workshops, assembling education and policy experts to consider the long-term strategic vision for student equity in HE. The equity roadmap emerged from these workshops and was further honed via national consultation and roundtables held in every state and territory. Thus, the policy vision ultimately developed was the product of a collaborative and iterative action research methodology, forward looking yet respectfully acknowledging the policy document that has framed Australian HE equity policy for the past three decades, A Fair Chance For All (Department of Employment, Education and Training, 1990).

The equity roadmap was drafted to be apolitical, positive and broad, whilst maintaining fidelity to diverse national perspectives surfaced throughout the consultation process. It provides a clear and compelling narrative for student equity and a conceptual roadmap for actionable policy. The integrated success statement for Student Equity 2030 is quoted below.

\section{THE BEST CHANCE FOR ALL}

\section{Australia's future depends on all its people, whoever and wherever they are, being enabled to successfully engage in beneficial lifelong learning.}

Contributing to: A fair, democratic, prosperous, and enterprising nation; reconciliation with Indigenous Australia; cultural, civic and intellectual life.

Achieved by: An inclusively designed system with multiple entry and exit points; proactive removal of barriers to participation; and tailored support where needed.

Accountable through: An integrated approach to measuring success at institutional and national levels to align performance with policy objectives.

This equity roadmap posits that student equity is integral to all stages of the education ecosystem and is a necessary condition for a fair, democratic, prosperous and enterprising nation. The visibility of COVID-19's diverging impact on different social groups has seen equity considerations - across the gamut of academic, psychosocial, financial, health and personal dimensions - move from the educational periphery to the mainstream with digital poverty, financial precarity and mental wellbeing being issues that have been particularly highlighted.

These are the matters to which we now turn, in a spirit of pragmatic optimism and desirous of not wasting a crisis. But, as champions are well-aware, there are no quick fixes here; our equity policy settings need to deliver education and training as substantive social justice and mobility tools that can help rebuild a slowing economy and assure societal wellbeing for the longer term. In all of this complexity, we now present the outworking of our reciprocal, reflective and reflexive discussions, organised under the five strategic themes utilised within the equity roadmap. 


\section{Theme 1 - A Holistic Notion of Student Equity: From Legacy Equity Groups to Access for All}

Australia has a mature and sophisticated equity policy framework that stretches back to system genesis. Three decades of bipartisan support have ensured that student equity is deeply enmeshed in the HE policy fabric. This is due in large measure to the legacy of A Fair Chance For All, developed as part of the Dawkins-era HE reforms in the late 1980s (Harvey et al., 2016). A Fair Chance For All galvanised a sustained and powerful coalition of practitioners and researchers, while the principles it espoused remained embedded in signature policy developments across subsequent decades. Denise Bradley was a driving force in the development of A Fair Chance For All and went on to entrench equity policy principles in the design of both the demand driven funding system (Bradley et al., 2008) and the equity flagship Higher Education Participation and Partnerships Program (HEPPP). Together, these policies disrupted stable patterns of underrepresentation, with greater inclusion as the result (Zacharias, 2017).

Throughout 2020, the disadvantage experienced by those on the margins of HE has been exacerbated by the combined effects of technological disruption to economic and social systems (marked by weak growth in demand for low skill labour) and by COVID's abrupt contraction in economic activity (displacing lower skilled hospitality and retail workers). While Australia has an international reputation for equity policy (Salmi, 2019), the goal of an inclusive HE system remains elusive. It is the case that systemic exclusion persists in HE.

One example of such systemic exclusion is the participation of students with disabilities. This exclusion is exemplified by the absence of this group from the JRGP consolidation of equity funding (Department of Education, Skills and Employment, 2020a). While it could be argued that many students with disabilities are picked up across the other equity groups, particularly given the link between poverty and disability, in reality, students with disabilities are not defined by their categorisation. Disability is dynamic and individual characteristics intersect with environments, gender, place, sexuality, socioeconomic and other factors. Resolving such systemic exclusion requires us to think holistically about the broader context and intersectionality, particularly if there is to be continued exclusion from labour markets.

A holistic notion of student equity also requires tertiary educators, leaders and policy makers to think critically about educational (in)equity for all students transitioning to post-secondary study. For example, school students in 2020 faced considerable disruption, shifting from learning at school, to home and back again, with some adjusting better than others. Assessments of student learning and potential will likely favour those with more social, economic and cultural capital, who had access to safe and study-friendly spaces at home and to technology with stable internet. The long-term developmental effects of lockdown are still to be revealed but there are already predictions of a 'shadow' pandemic of mental ill-health (Carbone \& Jorm, 2020). The authors have previously argued that substantive equity for all requires recalibration of assumptions about prerequisite knowledge and skills, and dedicated attention to successful first year transition. Preliminary reports suggest differential impacts of COVID lockdowns across cohorts that will require HE to be more attuned to the characteristics of each specific intake (Heffernan, 2021). In COVID-19 times, there is a risk that transition support for under-prepared students may be further compromised by educators necessarily focused on emergency remote teaching, referred to by some as 'panic-gogy' (Kamenetz, 2020).

There have been few if any policy levers in place to ensure educational equity is considered holistically across the life course. Different starting points and differential impacts of socio-economic disadvantage lead to divergent levels of preparedness to adapt to changing future workplaces. Positive exemplars of policy activity that look to the big picture are the Review of the Australian Qualifications Framework (AQF) (Noonan et al., 2019) and the Review of Senior Secondary Pathways (Department of Education Skills and Employment, 2020b). Both reviews are commended for their emphasis on learners' assured access to diverse and flexible pathways and quality careers advising for informed decision-making. But while the Pathways Review is holistic in its framing and future focus, its senior secondary emphasis quite obviously accounts for only one part of the education ecosystem. Policy holism directed to ecosystemic integration is critical and is discussed in the next parts.

\section{Theme 2 - An Integrated Approach to 'Success': In Support of 'Stats and Stories'}

The equity roadmap articulated a notion of 'success' that reflects the ideal of universal access to tertiary education at the time and in the form that is most beneficial to the individual. Throughout the consultation that led to the roadmap, stakeholders were vocal in the view that conceptions of success should include an appropriate blend of valid quantitative indicators (statistics) 
and contextual narrative (stories). This integrated approach to success contrasts with legacy policies that more passively promote equality of opportunity (Higher Education Funding Act 1988 (Cth), s.22.1; Higher Education Support Act 2003 (Cth), s.41.10). The integrated approach focusses on more nuanced quantitative measures evidenced through associated statistical collections.

The language of 'equality of opportunity' in HE legislation maintains a notion of success which is grounded in liberal concepts of choice (Friedman, 1982), native talent (Rawls, 1971) and equality before the law (for example, Australian Human Rights Commission, 2020). Even recent attempts to 'widen participation', which was the dominant framing of student equity policy in Australia from 2009 and in the UK from the late 1990s, have been criticised by scholars. Burke (2012) and Southgate and Bennett (2014) argue that widening participation policy and programs do not conceptualise the problem they are trying to address in its historical, structural and sociocultural complexity. Giving equal treatment or opportunity to people positioned on a diverse continuum of advantage and disadvantage will fail to address systemic barriers to participation. More targeted interventions are necessary to achieve 'substantive equality' (Barnard \& Hepple, 2000).

In response to these critiques, the equity roadmap sought to move away from the neoliberal concepts of the "cap(able) [sic] individual" and "the proper aspirant" (Southgate \& Bennett, 2014, p. 21). It positions "all Australians, whoever and wherever they are" as the target group for policy; and reframes "the neoliberal project of self-improvement through higher education" (Burke, 2012, p. 30) by introducing more subjective notions of success. The document is deliberately vague on what might constitute "beneficial lifelong learning" in order to encompass the diverse hopes and individualistic motivations that drive participation in post-secondary education, especially in an Industry 4.0 and post-COVID world where productive learning pathways are likely to be non-linear and multi-directional. Overall, the equity roadmap adopts a positive and inclusive framing - enabling individual success in tertiary education as central to fair and prosperous nation-building. This framing sits quite easily with the imperative for economic and social recovery in a pandemic-induced recession where many workers have suffered job loss, including quite early or very late in their working lifespan. The equity roadmap emphasises the proactive removal of barriers to enable lifelong learning participation, augmented with targeted individual support and quality careers advising.

Unfortunately, an immediate policy response to COVID-19 has been the passage of the JRGP, which is likely to impact negatively on successful HE participation by equity group students. For example, the JRGP includes measures that problematise failure. Students who fail $50 \%$ of their first-year units will no longer be eligible for Government subsidised places or student loans in their course of study. These provisions will add "stress for students who are already struggling with their life load and [are] likely to punish those who are already disadvantaged" (Zacharias \& Ajjawi, 2020, n.p.). JRGP also cements declining investment by the Commonwealth in HE. From 2020-21 to 2024-25, Commonwealth investment in HE falls by $\$ 1$ billion, whilst investment in private school education rises by $\$ 3.7$ billion (Commonwealth of Australia, 2021, p. 169). At a time when we need to invest in all people to 'learn our way out of recession', the JRGP is a return to a competitive regime where the inequalities created by socioeconomic status, location and race re-enter the arena of tertiary education access, participation and success, underpinned by crude quantitative-centric metrics.

We know an integrated approach can work for both policy design and evaluation. The Kemp-Norton Review (2014) demonstrated that macro drivers of demand driven funding, combined with targeted and contextual outreach through HEPPP, successfully increased the participation rate of students from low-SES backgrounds and most other equity groups. Stubbornly persistent levels of underrepresentation were disrupted and the relative contributions of these policies has been revealed through a mixed-methods 'stats and stories' approach (Zacharias, 2017). Missing in these policy responses (again) was the strategic integration with VET and an ecosystemic approach to secondary pathways, which constrained the achievement of sustainable universal access and the activation of lifelong learning.

\section{Theme 3 - Sector Differentiation and Institutional Diversity}

Smooth transitions and better outcomes for students across a diversified but balanced tertiary system are essential for engagement in 'beneficial lifelong learning'. Equal and equitable access to educational opportunity for all learners across the lifespan, appropriate to individual life-stage, experience and needs, enables participation in the full range of life opportunities, including meaningful paid work and active civic engagement. Realising this vision requires policies and systems for educational 
infrastructure very different from those of our current siloed sectors (schooling, VET, HE, hybrid VET-HE and workplace learning and experience). It requires inclusive system design to support universal and iterative tertiary education access.

Recent years have seen market share increase across tertiary education, captured by universities that operate with near identical business models in pursuit of enrolment and revenue growth. In contrast, the capacity of the VET sector has been curtailed by years of policy misadventures, exemplified by what has been termed the "VET FEE-HELP debacle" (Warburton, 2016). A holistic notion of equity, and an integrated approach to success, requires investment in high-quality VET and HE and VET-HE hybrids, rather than reallocating money to one institutional form at the expense of others. The current system results in many disadvantaged Australians being cycled through lower level qualifications that provide little by way of transferrable skills from one occupation to another (Noonan et al., 2019; Yu et al., 2012). By contrast, those undertaking doctoral studies are primarily drawn from the most advantaged backgrounds (Department of Education, 2020). Whilst only some citizens are able to reach doctoral heights under current policies, Australia's future prosperity depends on all of its people being enabled to fulfil their potential, at whatever qualification level that may be.

Central to our thinking about sector differentiation and institutional diversity are the needs of students. Beyond 2020, student pipelines into tertiary education will include those whose schooling and social development have been impeded by lockdowns, digital poverty and social isolation. Many mature age learners will have been displaced from the labour market as a result of COVID economic adjustment and structural changes arising from Industry 4.0. Our future-focussed educational vision for Australia must be learner-centric and demand-led (UIL, 2020) and minimise institutional and/or inter-sectoral competition for status and resources. There are positive signs that a connected tertiary education ecosystem, capable of accommodating sector differentiation and institutional diversity, can be better nurtured. For example, the AQF Review (Noonan et al., 2019) recommended much-needed enhancements for credit transfer and recognition of prior learning to enable greater flexibility in learning aggregation. This is a concrete move away from the rigid sector hierarchies implicit in current sector silos. The challenge continues to be that of policy coherence across Australia's federated model for better alignment with the needs of all learners navigating the fallout of Industry 4.0 and COVID-19.

\section{Theme 4 - Industry Transition and Lifelong Learning}

The equity roadmap was developed pre-pandemic in the context of well-documented predictions of the impact that Industry 4.0 disruption would have on future work, skills and learning. At that time, technology-driven change in job tasks, industries and professions intersected with globalisation, demographic shifts and failure of national workforce planning. A more coherent and connected approach to post-compulsory education and training was seen by experts and stakeholders as vital for national fairness and necessary for social cohesion and advancement. At the start of the 2020s, COVID-19 has accelerated all of these trends and turbocharged technological adoption and transformation. Decades of predictions that telecommuting would be normalised have been realised overnight. Digital disadvantage has become visible in emergency remote education. Nation (re)building and healing beyond the pandemic require that prosperity and equity be pursued in tandem and that all actors should come together - government, industry, professions, educators, leaders, policy-makers, workers and learners - to co-create a holistic and positive future vision for sustainable industry transition and lifelong learning.

Fortunately, from a policy perspective, the AQF Review reported in late 2019 (Noonan et al., 2019). Seizing disruption's imperative to improve learning and employment outcomes, the Review's Expert Panel recommended that a future-focussed and contemporary approach to qualification design be adopted to enable all citizens' participation and productivity. In making the case for change, the Panel echoed points made by other reviews, peak bodies and thinktanks that "central economic and social policy goals" (2019, p. 8) mandated concerted action to:

- widen educational participation and improve educational attainment levels, particularly for individuals and regions with lower levels of both;

- enable pathways for young people to transition successfully from school to complete (at least) an initial tertiary qualification (Department of Education Skills and Employment, 2020b). This latter picks up consistent advice that more than $90 \%$ of new jobs expected to be created in Australia by 2024 will require a post-secondary qualification (Department of Employment, Skills, Small and Family Business, 2020);

- reconceive post-secondary education as no longer "linear and hierarchical" but rather as a connected tertiary sector with parity of esteem and "better linkages and pathways between ... VET and higher education" (Noonan, et al., 2019, p. 8); 
- assure that qualifications, their purposes, outcomes and inter-relationships, are well-understood, relevant and trusted by employers and all (young and mature) learners alike;

- enable "ready, flexible access to a broad suite of options and opportunities for developing new skills" (Noonan, et al., 2019 , p. 8), including shorter form credentials; and

- assure that credit and prior learning recognition is "easier to access, more transparent, and rigorous" (Noonan, et al., 2019 , p. 8), both within and between sectors.

Underpinning these reforms, set out here as a coherent articulation of a roadmap for post-pandemic action, is the dual acceptance that "[1]ifelong learning must become a practical reality for people" (AlphaBeta, 2019; Noonan, et al., 2019, p. 8) and that future productivity is founded on the assumption of a universal entitlement to tertiary education (Kift, 2020). We have sought to represent such a "connected lifelong learning ecosystem" in Figure 1 (Kift, 2020), inclusive of various forms of formal, nonformal and informal learning that future workers are increasingly likely to access over the course of their lifelong learning.

\section{Figure 1}

Connected Lifelong Learning Ecosystem (Kift, 2020)

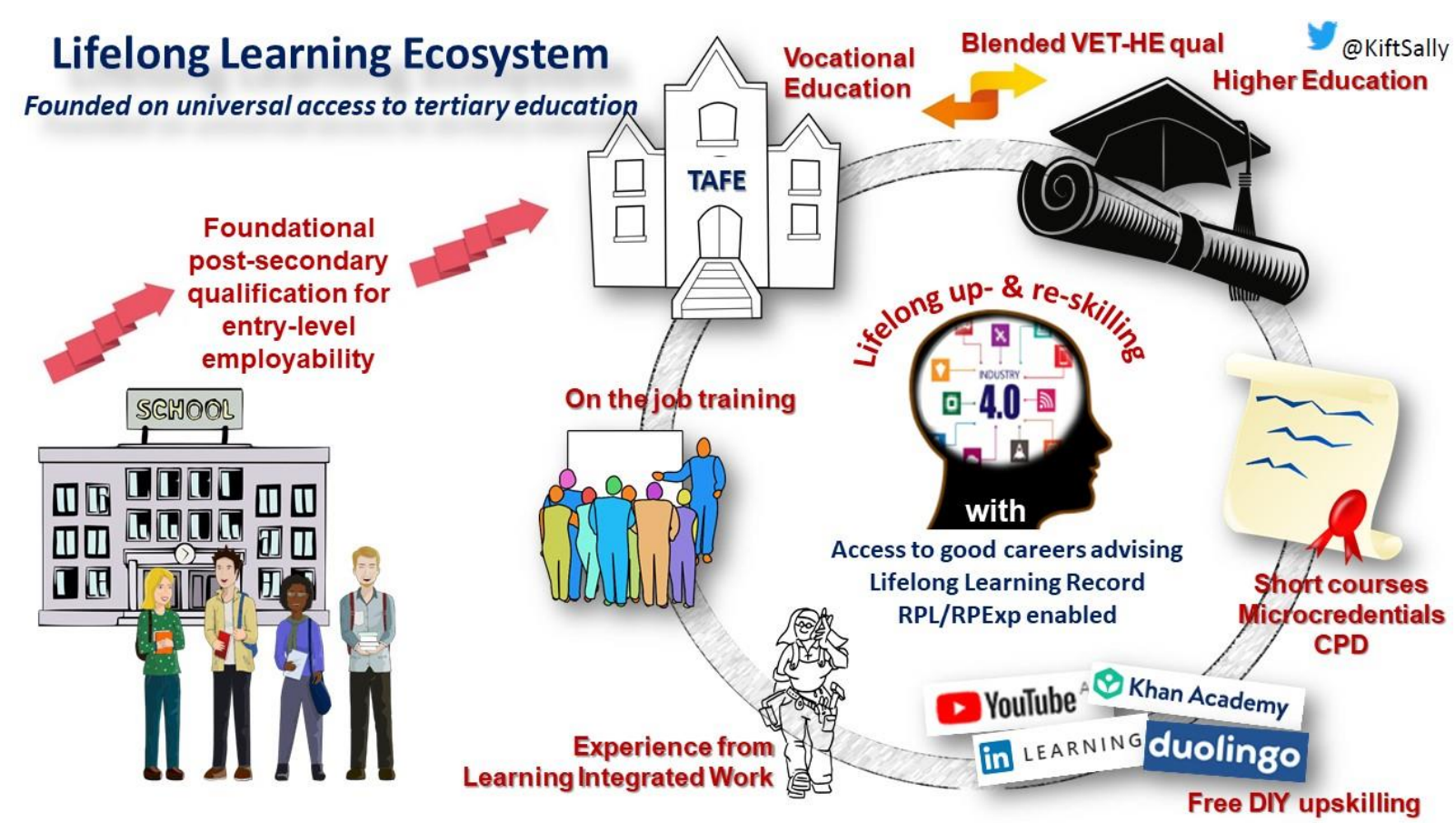

We note that the up- and re-skilling potential of micro-credentials in times of labour market precarity has been embraced wholeheartedly by government and others (see, for example, the recent addition to the AQF of the 'Undergraduate Certificate' as a pandemic re-training response which may provide another pathway into degrees). In the context of our expansive vision for educational equity post-COVID-19 however, we note UNESCO's reservations (Chakroun \& Keevy, 2018, p. 37) that:

There is an inherent risk associated with open degrees and micro-credentials that the 'whole will not be greater than the sum of the parts.' Stated differently, the risk is that the stacking to form a macro-credential will not be conceptually sound and as a result, it will not be recognizable by employers. Hence stacking (the combination of microcredentials) may not always lead to coherent qualifications.

It would be a poor outcome for national recovery if under-represented equity groups and individuals were enticed to forego the less-risky quality assurance of macro-qualifications on the basis of an untested promise of 'stackable' micro-learning coherence. As the government's own Department of Employment, Skills, Small and Family Business (2020) has forecast, and as the 
Business Council of Australia (2017) has endorsed, formal qualifications will remain important for entry-level transition to the workforce.

In all of this, educational equity over the expanded lifelong learning continuum envisages warmer handovers, better alignment and increased permeability between currently siloed education sectors of schooling, VET, HE, hybrid VET-HE and workplace learning and experience. This includes quality assured and fit-for-industry-purpose continuing professional development and on-the-job training in Industry 4.0 workplaces. As we and many others have identified, lifelong educational equity is further underpinned by access to quality careers advising, career development learning and the life-wide aggregation and curation of all learning by agentic learners (Kift, 2020); for example, in an interoperable learning record (American Workforce Policy Advisory Board, 2019; Department of Education, Skills and Employment, 2020b). COVID-19 has only sharpened these imperatives.

\section{Theme 5 - Accountability, Capability and Transparency}

Preceding sections have highlighted the gap between the long-term vision of the equity roadmap and current reality. Bridging this gap is difficult but achievable if policy better embeds accountability, builds appropriate capabilities and commits to transparency. Tertiary education can readily collect the right information, ideally via a Unique Student Identifier (USI) that enables longitudinal studies of outcomes and impact at the cohort level. A USI would enable triangulation of quantitative and qualitative data for evaluation in nationally consistent ways. Valid data would support better-targeted and evidence-based consequences that link future funding to past outcomes. Without timely and nuanced data-driven insights, HE policy is inevitably built on poor foundations and produces sub-optimal outcomes.

In a transparent system, institutions would be enabled to evaluate the structural bases for persistent failure of some students and be held accountable for the academic outcomes of the students they admit and the quality of education they deliver, rather than having to penalise students who fail early as the JRGP now requires. Better information provision and careers guidance, individualised across the secondary and tertiary span, will ensure that learners are positioned to make informed choices about the range of educational and training pathways available to them. Currently, many school leavers flounder in their decisionmaking processes regarding post-secondary options (Raciti, 2019). In a capable and transparent system, adult learners would also have greater choice in when, how and where they learn across diverse and flexible learning sites and types, similarly facilitated by high quality careers advising.

Sustainable progress towards a long-term policy view that delivers a coherent and connected lifelong learning ecosystem, with easy movement between sectors of equal status, is possible but will take a serious break with policy tradition. Over the past 20 years, HE policy has been one of the most tinkered-with policy areas at the Commonwealth level. Key financing legislation has been amended more than four times per year on average, across nearly two decades (Higher Education Support Act 2003, Endnote 3). Performance based funding had promise for driving greater accountability, but before its full implementation, was superseded by the JRGP. Stable policy that is informed by a coherent vision for the renewal of post-secondary education, and fully implemented, evaluated and refined over time, should be the long-term goal that galvanises community, education and industry in a united approach to compel inter-governmental action.

\section{Summary of Findings}

Throughout 2020, three keen proponents of Australian HE equity employed an action research methodology to make sense of the impact and future influence of the COVID-19 pandemic on Australian post-secondary education. These conversations influenced our professional responses to the pandemic and enabled a rich exploration of its policy implications. We acknowledge the limitations of the action research methodology in this application, especially given the limited empirical evidence available at the time of writing. In the absence of available 2020 data, due to the lag time in Australian HE data publication, we have drawn primarily on the contemporaneous evidence available of COVID-19's effect on educational equity and our own lived professional experience of the pandemic's impact, utilising the equity roadmap as the objective framing in efforts to avoid subjective bias in our analysis. The roadmap proved to be a robust framework for sharing our distinct experiences and for charting the contours of policy reforms that would support an immediate and longer-term sustainable recovery. Critically, COVID-19 has validated and accelerated the future of learning and work canvassed in the equity roadmap, 
which is now playing out in an economy in recession and in circumstances of high under- and unemployment, especially for young people.

The issues of how best to re- and up-skill displaced workers at scale via short courses, and how learners might be provided with productive education and training opportunities that harness the best of both VET and HE, have become acute and central to economic recovery. While the current focus on HE short courses may well support the return to employment of some displaced workers, the shorter form credentials response presents significant risks for student equity, especially absent an ecosystemic approach and policy framing. Short course supply will do little to address the needs of groups already subject to systemic exclusion. For students left behind by poor remote learning experiences in secondary schooling, tertiary education must do much more to understand and respond to their specific needs. Both system and institutional policy will increasingly be expected to accommodate the individual learning needs of all Australians. Valid quantitative data should be contextualised by personal narratives, deployed toward beneficial ends. Access to high quality, evidence-based careers advising is now even more urgent and requires equitable rollout at scale.

We argue that national policy implementation should embrace the equity roadmap's vision of multi-directional and agentic lifelong learning. The array of reviews, reports, programs and initiatives that various state, territory and federal governments have rolled out in an uncoordinated wave of well-intentioned crisis mediation - a post-pandemic panic - need to be joined up, learner-centric and coherently underwritten by equity and inclusion principles.

The grand challenge our nation faces of pursuing economic and social wellbeing in a post-pandemic world, and the harnessing of education and training as one critical response to it, is an imperative recognised globally. It is validating, therefore, to see the equity roadmap's future visioning now reflected in the recent UNESCO work of the UIL (2020), which suggests that lifelong learning be considered both a common good and a human right. The UIL's framing of a culture of lifelong learning aligns with the equity roadmap's imagining and sees learning as occurring anytime (from birth to death) and anywhere (in and out of the education system, formal, non-formal and informal) and being undertaken by anyone (all peoples) about anything (via a range of modalities and across all domains). The pervasiveness of lifelong learning in this conceptualisation as central to major national policy goals is powerful; aligned to the equity roadmap's ethos, but more ambitiously articulated. The UIL speaks of: societies that understand themselves as learning societies; people who identify as learners across their lifespans; of schools and tertiary institutions transformed into lifelong learning institutions for all community members; and of "lifelong learning culture [being] rooted in the labour market, which means reengineering and revitalizing workplace learning" (2020, p. 39). This is truly The Best Chance for All writ large. And it is an actionable roadmap for post-pandemic policy that is not panicked but nation-building in its articulation of an educational future inclusive of all and delivering a long-term bulwark against inequalities and inequities. 


\section{References}

AlphaBeta. (2019). Future skills. AlphaBeta. https://www.alphabeta.com/wp-content/uploads/2019/01/google-skillsreport.pdf

American Workforce Policy Advisory Board. (2019). White paper on interoperable learning records. Data Transparency Working Group.

Australian Human Rights Commission. (2020). Positive discrimination. Sydney: AHRC. https://humanrights.gov.au/quickguide/12078

Barnard, C., \& Hepple, B. (2000). Substantive equality. Cambridge Law Journal, 59(3), 562-585. https://doi.org/10.1017/S0008197300000246

Bradley, D., Noonan, P., Nugent, H., \& Scales, B. (2008). Review of Australian higher education final report. Department of Education, Employment and Workplace Relations. https://www.voced.edu.au/content/ngv\%3A32134

Bridgman, P., \& Davis, G. (2004). The Australian policy handbook. Allen \& Unwin.

Burke, P. J. (2012). The right to higher education: Beyond widening participation. Routledge.

Business Council of Australia. (2017). Future-Proof: Protecting Australians through education and skills. Business Council of Australia. https://www.voced.edu.au/content/ngv\%3A77837

Carbone, S., \& Jorm, A. (2020, April 30). We need to flatten the 'other' coronavirus curve, our looming mental health crisis, The Conversation. https://theconversation.com/we-need-to-flatten-the-other-coronavirus-curve-our-looming-mentalhealth-crisis-137170

Chakroun, B., \& Keevy, J. (2018). Digital credentialing: Implications for the recognition of learning across borders. United Nations Educational, Scientific and Cultural Organization.

Commonwealth of Australia. (2021). Budget strategy and outlook. budget paper No. 1. 2021-22. https://budget.gov.au/202122/content/bp1/download/bp1_2021-22.pdf

Department of Employment, Education and Training. (1990). A fair chance for all: Higher education that's within everyone's reach. Australian Government Publishing Service. https://www.voced.edu.au/content/ngv\%3A2270

Department of Education. (2020). Student equity in higher degrees by research statistical report, August 2019. https://www.dese.gov.au/higher-education-statistics/resources/student-equity-higher-degrees-research

Department of Education, Skills and Employment. (2020a). Job-ready graduates discussion paper. https://www.dese.gov.au/job-ready/resources/job-ready-graduated-discussion-paper

Department of Education, Skills and Employment. (2020b). Looking to the future - Report of the review of senior secondary pathways into work, further education and training. https://www.voced.edu.au/content/ngv\%3A87244

Department of Employment, Skills, Small and Family Business (2020) Employment outlook to May 2024. https://cica.org.au/wp-content/uploads/Employment-Outlook-to-May-2024.pdf

Friedman, M. (1982). Capitalism and freedom. The University of Chicago Press.

Harvey, A. (2020, May 10). Helping disadvantaged students deal with COVID-19. Campus Morning Mail. https://campusmorningmail.com.au/news/helping-disadvantaged-students-deal-covid-19/

Harvey, A., Burnheim, C., \& Brett, M. (2016). Towards a fairer chance for all: Revising the Australian student equity framework. In A. Harvey, C. Burnheim, \& M. Brett (Eds.), Student equity in Australian higher education: Twenty-five years of a fair chance for all. Springer.

Heffernan, M. (2021, May 21). Some high school students 'haven't developed' after their year in lockdown. The Age. https://www.theage.com.au/national/victoria/some-high-school-students-haven-t-developed-after-their-year-in-lockdown20210504-p57oot.html

Jones, B. D., \& Baumgartner, F. R. (2005). The politics of attention: How government prioritizes problems. University of Chicago Press.

Kamenetz, A. (2020, March 19). 'Panic-gogy': Teaching online classes during the Coronavirus pandemic, National Public Radio https://www.npr.org/2020/03/19/817885991/panic-gogy-teaching-online-classes-during-the-coronavirus-pandemic

Kemp, D., \& Norton, A. (2014). Review of the demand driven funding system: Report. Department of Education. https://www.dese.gov.au/higher-education-reviews-and-consultations/resources/review-demand-driven-funding-systemreport

Kift, S. (2020, November 17-18). Higher education leading the change?: Enabling a lifelong learning ecosystem [Keynote]. 2020 UNSW L\&T Forum, Sydney, Australia.

Marshman, I., \& Larkins, F. (2020). Modelling individual Australian universities resilience in managing overseas student revenue losses from the COVID-19 pandemic. Centre for the Study of Higher Education. University of Melbourne. https://melbourne-cshe.unimelb.edu.au/lh-martin-institute/insights/modelling-individual-australian-universities-resiliencein-managing-overseas-student-revenue-losses-from-the-covid-19-pandemic

Noonan, P., Blagaich, A., Kift, S., Lilly, M., Loble, L., More, E. \& Persson, M. (2019). Review of the Australian qualifications framework. Final report 2019. Department of Education. https://www.dese.gov.au/reviews-andconsultations/australian-qualifications-framework-review 
Plibersek, T. (2020). Lessons learnt: Education in recovery. In T. Plibersek (Ed.), Upturn: A better normal after COVID-19 (pp. 149-158). New South Publishing.

Raciti, M. (2019). Career construction, future work and the perceived risks of going to university for young people from low SES backgrounds: Research fellowship final report. National Centre for Student Equity in Higher Education. https://www.ncsehe.edu.au/publications/perceived-risks-of-going-to-university/

Rawls, J. (1971). A theory of justice. Harvard University Press.

Robertson, J. (2000). The three Rs of action research methodology: Reciprocity, reflexivity and reflection-on-reality, Educational Action Research, 8(2), 307-326 https://doi.org/10.1080/09650790000200124

Salmi, J. (2019). Measuring the impact of equity promotion policies: Lessons from national and institutional case studies. Lumina Foundation

Schleicher, A. (2020). The impact of COVID-19 on education - Insights from education at a glance 2020. OECD.

Sonnemann, J., \& Goss, P. (2020). COVID catch-up: Helping disadvantaged students close the equity gap. Grattan Institute. https://apo.org.au/node/306245

Southgate, E., \& Bennett, A. (2014). Excavating widening participation policy in Australian higher education: Subject positions, representational effects, emotion, Creative Approaches to Research, 7(1), 21-45. https://www.voced.edu.au/content/ngv\%3A63282

Stone, C., \& David, M. (2020). New evidence: Stark inequity of online access for rural and remote students. AARE Blog. https://www.aare.edu.au/blog/?tag=inequity-in-australian-higher-education

Thomas, J., Barraket, J., Wilson, C.K., Holcombe-James, I., Kennedy, J., Rennie, E., Ewing, S., \& MacDonald, T. (2020). Measuring Australia's digital divide: The Australian digital inclusion index 2020. RMIT and Swinburne University of Technology, for Telstra. https://apo.org.au/node/308474

Tija, T., Marshman, I., Beard, J., \& Baré, Elizabeth (2020) Australian university workforce responses to COVID-19 pandemic: Reacting to a short-term crisis or planning for longer term challenges? LH Martin Institute, University of Melbourne. https://melbourne-cshe.unimelb.edu.au/lh-martin-institute/fellow-voices/australian-university-workforceresponses-to-covid-19-pandemic

UNESCO Institute for Lifelong Learning. (2020). Embracing a culture of lifelong learning: Contribution to the futures of education initiative. https://uil.unesco.org/lifelong-learning/embracing-culture-lifelong-learning

United Nations. (2020). Policy brief: Education during COVID-19 and beyond. https://www.un.org/development/desa/dspd/wp-content/uploads/sites/22/2020/08/sg_policy_brief_covid19_and_education_august_2020.pdf

Warburton, M. (2016). The VET FEE-HELP debacle: Helping its victims and lessons for administration. https://www.voced.edu.au/content/ngv\%3A74705

Yu, S, Bretherton, T, Schutz, J., \& Buchanan, J. (2012). Understanding the nature of vocations today: Exploring labour market pathways. National Centre for Vocational Education Research. https://www.ncver.edu.au/research-andstatistics/publications/all-publications/understanding-the-nature-of-vocations-today-exploring-labour-market-pathways

Zacharias, N. (2017). The Australian student equity programme and institutional change: Paradigm shift or business as usual. National Centre for Student Equity in Higher Education. https://www.ncsehe.edu.au/publications/the-australianstudent-equity-programme-and-institutional-change-paradigm-shift-or-business-as-usual/

Zacharias, N., \& Ajjawi, R. (2020, August 20). When students fail, many do nothing about it. Here's how unis can help them get back on track. The Conversation. https://theconversation.com/when-students-fail-many-do-nothing-about-it-hereshow-unis-can-help-them-get-back-on-track-144563

Zacharias, N., \& Brett, M. (2019). The best chance for all. National Centre for Student Equity in Higher Education. https://www.ncsehe.edu.au/publications/the-best-chance-for-all/

\section{Please cite this article as:}

Kift, S., Zacharias N., \& Brett, M. (2021). The best chance for all: A policy roadmap for post-pandemic panic. Student Success, 12(3), 26-36. https://doi.org/10.5204/ssj.1782

This article has been accepted for publication in Student Success. Please see the Editorial Policies under the 'About' section of the Journal website for further information.

Except where otherwise noted, content in this journal is licensed under a Creative Commons Attribution 4.0 International Licence. As an open access journal, articles are free to use with proper attribution. ISSN: 2205-0795 